\title{
GAMBARAN KEBOCORAN TEPI TUMPATAN PASCA RESTORASI RESIN KOMPOSIT PADA MAHASISWA PROGRAM STUDI KEDOKTERAN GIGI ANGKATAN 2005-2007
}

\author{
${ }^{1}$ Theo Mukuan \\ ${ }^{2}$ Jemmy Abidjulu \\ ${ }^{3}$ Dinar A Wicaksono
}

\author{
${ }^{1}$ Kandidat Skirpsi Program Studi Kedokteran Gigi Fakultas Kedokteran \\ Universitas Sam Ratulangi Manado \\ ${ }^{2}$ Bagian Matematika dan Ilmu pengetahuan Alam Universitas Sam Ratulangi Manado \\ ${ }^{3}$ Bagian Konservasi Gigi Program Studi Kedokteran Gigi Universitas Sam Ratulangi Manado \\ Email: TheoMukuan@yahoo.com
}

\begin{abstract}
Composite resin is one of the restoration material which has the advantage in aesthetic due to its colour. This make the composite resin as a material of choice, unfortunately most of patients who have received composite resin treatment doesn't have a proper careness to its own restoration after treatment. Aim: to study how many people who use composite resin as restoration material and to study if the restoration has any leakage after treatment. Results: the study showed that women have more composite resin restoration than men. The leakage occurred to three different subject in this research which is the most leakage happened to 2007's student, followed by 2006's and 2005's. Class one Black classification is the most restoration to be found in this study followed by class 4 , class 5 , class 3 , and class 2 . The leakage which found in this study mostly occurred to molar restorations, followed by premolars while incicivus was found to be the least.
\end{abstract}

Keywords: resin, composite, leakage, restoration.

\begin{abstract}
Abstrak: Resin komposit merupakan salah satu jenis bahan tumpatan yang memiliki keunggulan dalam bidang estetik karena merupakan bahan tumpatan yang sewarna dengan gigi. Hal ini menjadikan resin komposit sebagai bahan pilihan restorasi, namun banyak pasien yang telah mendapatkan perawatan restorasi resin komposit kurang memperhatikan tumpatan pasca restorasi tersebut. Tujuan: penelitian ini bertujuan untuk mengetahui gambaran penggunaan resin komposit sebagai bahan tumpatan gigi pada restorasi kavitas dan mengetahui apakah telah terjadi kebocoran tepi tumpatan resin komposit pada perawatan restorasi kavitas. Hasil penelitian: menunjukkan distribusi penggunaan komposit lebih banyak pada perempuan dibandingkan laki-laki. Terjadi kebocoran tumpatan pada subjek penelitian dari tiga angkatan yang berbeda yaitu terbanyak pada mahasiswa angkatan 2007 kemudian 2006 dan 2005. Tumpatan kavitas kelas I merupakan tumpatan yang paling banyak diikuti kelas 4, kelas 5, kelas 3, dan kelas 2. Kebocoran gigi yang ditemukan pada penelitian ini terjadi paling banyak pada gigi molar kemudian premolar sedangkan insisivus paling sedikit.
\end{abstract}

Kata kunci: resin, komposit, kebocoran, restorasi.

Karies merupakan suatu penyakit pada gigi yang paling sering ditemui di kehidupan sehari-hari. Karies yang terdapat pada gigi depan akan sangat mengganggu dari segi estetik penderita, karena itu perlu bahan tumpatan yang bukan hanya kuat tetapi juga 
dilihat dari estetiknya terlihat baik. Resin komposit merupakan salah satu jenis bahan tumpatan yang paling populer karena memiliki keunggulan dalam bidang estetik dan merupakan bahan tumpatan yang sewarna dengan gigi. Namun, umumnya pasien yang telah melakukan restorasi kavitas kurang memperhatikan tumpatan pasca restorasi tersebut. Karena itu perlu dilakukan evaluasi lebih lanjut pada pasien yang telah melakukan restorasi kavitas. Pemeriksaan ini berguna untuk melihat apakah tumpatan tersebut masih sama saat pertama dilakukan restorasi atau telah terjadi perubahan pada tumpatan tersebut, yang mengakibatkan ketidaknyamanan dari pasien yang telah melakukan perawatan restorasi kavitas itu sendiri.

Belum adanya data tentang tumpatan menggunakan resin komposit pada mahasiswa kedokteran gigi merupakan hal yang menarik. Terlebih mahasiswa bisa jadi tolak ukur yang penting karena berusia muda dan mempunyai rasa ingin tahu yang besar tentang sesuatu hal khususnya mahasiswa yang menuntut ilmu di Kedokteran Gigi. Berdasarkan latar belakang yang ada, maka penulis ingin membahas Gambaran Kebocoran Tepi Tumpatan Pasca Restorasi Resin Komposit pada Mahasiswa Program Studi Kedokteran Gigi Angkatan 2005-2007.

Karies gigi adalah penyakit yang menyerang permukaan gigi-geligi yang terbuka dalam mulut yang berakibat kerusakan jaringan keras mahkota gigi. Setelah terjadinya resesi gingiva, karies juga akan menyerang bagian akar yang terbuka. Bila tidak dilakukan perawatan akan meluas ke pulpa gigi dan dapat merusak seluruh mahkota gigi. Hal ini kemudian dapat menimbulkan rasa sakit, terganggunya fungsi mastikasi, inflamasi jaringan gingiva, pembentukan abses, perubahan penampilan pasien dan efek-efek sosial yang berkaitan dengannya. Karies gigi mengakibatkan kerusakan jaringan keras melalui aksi bakteri pembentuk asam yang terdapat di permukaan gigi. Ini merupakan tahap awal terjadi demineralisasi permukaan yang lambat dari email gigi. Tahap ini berlangsung progresif dan berlanjut melalui email, melintasi pertautan email-dentin dan menuju ke dentin dan bila telah terjadi karies maka perlu dilakukan tindakan khusus seperti penumpatan dengan bahan restorasi yang sewarna dengan gigi. ${ }^{1}$

Dewasa ini, bahan restorasi resin komposit secara umum telah menjadi pilihan para dokter gigi untuk merestorasi lesi karies pada daerah proksimal yang sudah mengenai daerah insisal gigi, sesuai dengan kualitas estetik dan kemampuan bahan tersebut untuk berikatan dengan stuktur gigi. Resin komposit berkembang sebagai bahan restorasi karena kelebihannya, antara lain: sifat estetik yang baik, penghantar panas yang rendah, relatif mudah dimanipulasi, tahan lama untuk gigi anterior dan tidak larut dalam cairan mulut. ${ }^{2,3}$

Dari sudut pandang estetik resin komposit masih dan akan tetap merupakan loncatan besar dalam kemampuannya sebagai bahan restorasi estetik sewarna gigi yang bisa digunakan untuk merestorasi gigi pasien dan dibentuk langsung dalam mulut pasien oleh dokter gigi. Sampai saat ini belum ada restorasi lain yang memiliki penampilan yang alami dan dapat dibuat semirip mungkin dengan gigi asli yang dapat dibentuk langsung di dalam mulut selain dengan restorasi resin komposit., ${ }^{4,5}$

Namun, sebaik apapun restorasi yang telah dilakukan oleh dokter gigi tetaplah harus dilakukan kontrol untuk melihat adanya perubahan yang terjadi pada restorasi komposit. Kebocoran tumpatan merupakan hal yang dapat ditemukan baik pada restorasi yang telah lama maupun restorasi yang masih tergolong baru.

Kebocoran tepi didefinisikan sebagai celah mikroskopik antara dinding kavitas dan tumpatan yang dapat dilalui mikro organisme, cairan, molekul dan ion. Kebocoran tersebut dapat mengakibatkan berbagai keadaan seperti : karies sekunder I diskolorasi gigi, reaksi hipersensitif, bahkan dapat mempercepat kerusakan tumpatan itu sendiri. Terjadinya kebocoran tepi merupakan akibat kegagalan adaptasi tumpatan terhadap dinding kavitas. 
Kegagalan restorasi resin komposit dapat disebabkan oleh, perbedaan masing-masing koefisien thermal ekspansi diantara resin komposit, dentin dan enamel, penggunaan oklusi dan pengunyahan yang normal, dan kesulitan karena adanya kelembaban, mikroflora yang ada, dan lingkungan mulut bersifat asam. ${ }^{6-10}$

Untuk mendeteksi terjadinya kebocoran tepi tumpatan pada restorasi resin komposit maka harus dilakukan pemeriksaan klinis pada rongga mulut dengan cara pengamatan dan tes sensitivitas dengan menggunakan sonde. Bila telah terjadi kebocoran tepi pada tumpatan maka dampak pada gigi akan terlihat, yaitu telah terjadi karies sekuder, marginal stain, dan diskolorisasi gigi. ${ }^{7-24}$

Penyebab terjadinya kebocoran tepi tumpatan resin komposit adalah kegagalan adaptasi restorasi terhadap dinding kavitas akibat perbedaan koefisien thermal ekspansi resin komposit, dentin dan enamel, serta kesulitan karena adanya kelembapan mikroflora yang ada karena lingkungan mulut yang bersifat asam. Kebocoran tepi akan semakin membesar bila tidak ada sisa email yang mendukung. ${ }^{24-26}$

\section{METODE PENELITIAN}

Penelitian ini merupakan penelitian deskriptif. Penelitian ini akan dilakukan di Program Studi Kedokteran Gigi Fakultas Kedokteran Universitas Sam Ratulangi. Berlangsung pada bulan juli-agustus 2012 . Populasi pada penelitian ini yaitu seluruh mahasiswa Fakultas Kedokteran Universitas Sam Ratulangi. Populasi terjangkau pada penelitian ini berdasarkan survei awal yaitu mahasiswa Program Studi Kedokteran Gigi angkatan 2005-2007 yang berjumlah 191 orang.

Teknik pengambilan sampel yang digunakan yaitu dengan cara simple random sampling. Besar sampel dalam penelitian ini ditentukan dengan menggunakan rumus Slovin, sebagai berikut:

$$
n=\frac{N}{\mathrm{~N}(\mathrm{~d})^{2}+1}
$$

191

$$
\begin{aligned}
& n=\frac{1}{191(0,1)^{2}+1} \\
& n=65
\end{aligned}
$$

Keterangan, $\mathrm{n}$ : Jumlah sampel

$\mathrm{N}$ : Jumlah unit populasi

$\mathrm{d}$ : margin kesalahan $(0,1)$

\section{HASIL PENELITIAN}

Hasil penelitian berdasarkan klasifikasi tumpatan menunjukkan terdapat total 114 gigi yang ditumpat komposit dari 65 subjek penelitian dengan distribusi 87 gigi (76,31\%) dengan tumpatan kelas I yang terdiri atas 16 gigi (14,03\%) pada angkatan 2005, 29 gigi $(25,43 \%)$ pada angkatan 2006, dan 42 gigi (36,84\%) pada angkatan 2007. Tumpatan kelas II berjumlah 5 gigi dengan distribusi 1 gigi $(0,87 \%)$ pada angkatan 2005, 1 (0,87\%) gigi pada angkatan 2006, dan 3 gigi (2,63\%) pada angkatan 2007. Tumpatan kelas III berjumlah 5 gigi (4,38\%) dengan distribusi 4 gigi (3,50\%) pada angkatan 2006 dan 1 gigi $(0,87 \%)$ pada angkatan 2007. Pada tumpatan kelas 3 ini, penulis tidak menemukan adanya tumpatan komposit kelas III komposit pada angkatan 2005. Tumpatan kelas IV berjumlah 11 $(9,61 \%)$ gigi dengan distribusi 1 gigi (0,87\%) pada angkatan 2005 dan 10 gigi (8,77\%) pada angkatan 2007. Untuk tumpatan kelas IV ini, penulis juga tidak menemukan adanya tumpatan kelas IV pada angkatan 2006. Tumpatan kelas V berjumlah 6 gigi $(5,26 \%)$ dengan distribusi 4 gigi (3,50\%) pada angkatan 2006 dan 2 gigi 2 (1,75\%) pada angkatan 2007.

Hasil penelitian berdasarkan kebocoran yang terjadi diketahui dari total 65 subjek penelitian terdapat 7 orang $(10,76 \%)$ yang mengalami kebocoran tumpatan komposit dengan distribusi 1 orang (1,53\%) pada angkatan 2005, 4 orang (6,15\%) pada angkatan 2006, dan 2 orang (3,07\%) pada angkatan 2007 sedangkan sebanyak 58 orang $(89,63 \%)$ tidak mengalami kebocoran tumpatan. 
118 Jurnal e-GiGi (eG), Volume 1, Nomor 2, September 2013, hlm. 115-120

Berdasarkan elemen gigi yang mengalami kebocoran gigi diketahui dari total 114 gigi yang mendapatkan tumpatan komposit, hanya terdapat 7 gigi yang mengalami kebocoran tumpatan yaitu 1 gigi insisivus $(0,87 \%), 1$ gigi premolar $(0,87 \%)$, dan 5 gigi molar (4,38\%).

Gigi insisivus yang mengalami kebocoran merupakan gigi dengan lama penggunaan 3 tahun. Gigi insisivus ini mendapatkan tumpatan komposit kelas III.

Gigi lainnya yang mengalami kebocoran tumpatan yaitu gigi premolar pertama rahang atas kanan. Gigi ini mendapatkan perawatan tumpatan komposit kelas I sejak 4 bulan yang lalu.

Adapun gigi yang mengalami kebocoran tumpatan terbanyak yang ditemukan dalam penelitian ini adalah gigi molar baik molar pertama (3 gigi) maupun molar kedua (2 gigi). Molar tersebut ratarata merupakan gigi dengan lama penumpatan di atas 2 tahun dimana, terdapat 4 gigi yang telah mendapatkan tumpatan komposit kelas I sejak 6 tahun yang lalu sedangkan hanya 1 gigi molar yang mengalami kebocoran tumpatan dengan lama penumpatan 1 tahun.

\section{BAHASAN}

Hasil distribusi penggunaan komposit berdasarkan klasifikasi tumpatan pada penelitian ini menunjukkan bahwa penggunaan komposit lebih banyak digunakan untuk kavitas kelas I yaitu sebanyak 87 gigi (76,31\%) dibandingkan untuk tumpatan lainnya. Hal ini kemungkinan disebabkan kavitas kelas I merupakan kavitas yang paling sering terjadi. Kavitas kelas I dapat terjadi akibat pit dan fissur yang dalam sehingga dapat menyebabkan terjadinya retensi maupun impaksi makanan yang nantinya akan menjadi penyebab terjadinya karies gigi.

Hasil penelitian yang dilakukan oleh Shah dkk pada 1146 pasien yang berkunjung ke rumah sakit gigi dan mulut di Punjab pada tahun 2008 menunjukkan hasil bahwa dari 938 lesi karies yang ditemukan, karies pada permukaan oklusal gigi yang termasuk dalam kavitas kelas I klasifikasi GV Black merupakan tipe karies yang paling banyak ditemukan yaitu sebanyak 503 kasus (53,6\%). Penggunaan fluoride secara topikal pada daerah ini hanya mampu mencegah terjadinya karies sebanyak 20\% dibandingkan daerah lainnya seperti pada permukaan licin gigi yang mencapai $61 \%$ dan ada interproksimal yang mencapai $55 \%{ }^{27}$

Hasil distribusi penggunaan komposit berdasarkan banyaknya kebocoran yang terjadi yaitu dari total 65 subjek penelitian, kebocoran tumpatan hanya terjadi pada 7 orang $(10,76 \%)$ sedangkan 58 (89,63\%) lainnya tidak mengalami kebocoran tumpatan. Hal ini dapat dipengaruhi oleh beberapa faktor seperti tipe bahan tumpatan yang digunakan, kandungan yang ada pada bahan tumpatan,dan interaksi antara bahan tumpatan dengan gigi. Ziyad pada tahun 2008 meneliti terjadinya kebocoran pada tumpatan menyatakan bahwa terdapat beberapa faktor yang berkontribusi dalam menyebabkan terjadinya kebocoran tumpatan ini seperti penyusutan polimerisasi, ekspansi hidroskopik, dan siklus termal. Ziyad menjelaskan bahwa terjadinya penyusutan ketika polimerisasi merupakan salah satu faktor yang berperan langsung menyebabkan staining pada tepi antara gigi dan tumpatan, terjadinya fraktur, kebocoran tepi tumpatan, karies sekunder, dan sensitivitas setelah penumpatan. Penyusutan tumpatan sebesar 65-75\% terjadi dalam 10 menit pertama. Ekspansi hidroskopik juga dapat menyebabkan terjadinya kebocoran tepi tumpatan dimana hal ini akan terjadi ketika tumpatan komposit telah terkena dengan berbagai cairan dalam rongga mulut. Penyerapan air oleh komposit dapat menyebabkan terjadinya ekspansi dan terbentuknya microcrack atau retakan kecil pada tumpatan komposit. Siklus termal dalam hal ini tekanan termal dapat menjadi patogenik dalam dua cara yaitu tekanan mekanis yang dihasilkan oleh adanya perubahan termal dapat menyebabkan merambatnya retakan kecil tadi. Cara kedua yaitu terjadinya perubahan dimensi gap antara gigi dan 
tumpatan. Hal ini dapat digunakan untuk menjelaskan terjadinya kebocoran pada 7 orang yang mengalami kebocoran tersebut dimana masing-masing terjadi 1 kebocoran dengan distribusi kebocoran tumpatan yaitu 5 gigi molar, 1 gigi premolar, dan 1 gigi insisivus. $^{28}$

Berdasarkan hasil penelitian ini, juga diketahui bahwa kebocoran gigi yang ditemukan pada penelitian ini sebagian besar telah digunakan dalam waktu yang cukup lama. Total 5 kebocoran tumpatan yang terjadi pada gigi molar, 4 diantaranya telah digunakan dalam jangka waktu yang cukup lama yaitu 6 tahun dan 1 lainnya digunakan dalam waktu 1 tahun. Gigi insisivus yang juga mengalami kebocoran merupakan gigi dengan lama penggunaan 3 tahun. Hal ini dapat disebabkan oleh faktorfaktor yang telah disebutkan di atas. Beberapa penelitian yang dilakukan oleh peneliti sebelumnya juga tidak jauh berbeda. Penelitian yang dilakukan oleh Mendonca dkk pada tahun 2010 menyatakan bahwa pada perbandingan antara tumpatan direct komposit dengan inlay tidak terlalu jauh berbeda pada tahun pertama penggunaan dimana keduanya sama dalam hal perubahan warna gigi, sensitivitas setelah penumpatan, maupun karies sekunder yang tidak terjadi. Namun, kedua jenis restorasi ini mengalami marginal staining/discoloration. ${ }^{29}$

Penelitian terhadap hasil tumpatan yang lebih lama dilakukan oleh Karaman dkk pada tahun 2012 dimana mereka mengevaluasi hasil tumpatan setelah 2 tahun penggunaan. Mereka membandingkan 2 buah merk bahan komposit yaitu komposit dengan teknologi nanohibrid dengan resin komposit flowable. Mereka menemukan bahwa terdapat 3 gigi yang mengalami marginal staining/discoloration pada masing-masing kelompok. ${ }^{30}$

\section{SIMPULAN DAN SARAN}

Melalui penelitian ini dapat disimpulkan bahwa telah terjadi kebocoran tumpatan pada subjek penelitian dan kebocoran tumpatan paling banyak terjadi pada gigi molar kemudian premolar sedangkan insisivus merupakan yang paling sedikit. Adapun tumpatan kavitas kelas I merupakan tumpatan yang paling banyak dan diikuti kelas IV, kelas V, kelas III, dan kelas II. Penulis menyarankan dapat dilakukan penelitian lebih lanjut mengenai faktor yang berpengaruh terhadap terjadinya kebocoran tumpatan komposit. Selain itu, dapat dilakukan penelitian kebocoran tumpatan dengan bahan tumpatan yang berbeda.

\section{DAFTAR PUSTAKA}

1. Aripin D. Indikasi dan cara aplikasi berbagai tipe resin komposit yang beredar dipasaran. Jurnal Kedokteran Gigi. Bandung: FKG Universitas Padjadjaran; 2006: 20-1,23.

2. Baum. Buku ajar ilmu konservasi gigi (Edisi Ketiga). Jakarta: EGC, 1997; p.49-50, 255-6, 258-9, 269-73.

3. Rizky IM. Adhesi perlekatan tambahan resin komposit pada gigi. Medan: FKG Universitas Sumatera Utara; 2008; p.3-13.

4. Anusavice KJ. Buku Ajar Ilmu Bahan Kedokteran Gigi (Edisi Kesepuluh). Jakarta: EGC, 2004; p.194, 228-9, 231-4, 237-9, 247, 249, 445.

5. Syarfita PD. Pertimbangan yang mendasari segi estetik pada tumpatan komposit gigi anterior. Medan: FKG Universitas Sumatera Utara [homepage on the Internet]. 2008 [cited 2010 okt 10]; 14. Available from: URL;http//www.researchgate.net.

6. Irawan B. Material restorasi direk kedokteran gigi saat ini. Jakarta: FKG Universitas Indonesia, 2004; p.26.

7. Heasman $\mathbf{P}$, Giles $\mathbf{M}$. Hart's Dental Dictionary (Third Edition). Philadelphia: Elsevier, 2007; p.205.

8. Anusavice KJ. Sciense of Dental Materials (Eleventh Edition). Missuri: Elsevier Suanders, 2003; p.144-5, 402-3, 406, 418, 423-6, 436-7.

9. Indriani DJ. Komposit resin dalam esthetic dentistry. Jakarta: FKG Universitas Indonesia, 2007; p.827-8.

10. Sarianofeni S. penggunaan resin komposit untuk mengurangi resiko barodontalagia. Jurnal Kedokteran Gigi. Surabaya: FKG Yniversitas Hang Tuah, 2007; p.102

11. Composites - yesterday and today. Scientific documention [homepage on the Internet]. 2009 [cited 2010 Sep 7]; 5-6. Available from: URL;http//www.voco.com 
120 Jurnal e-GiGi (eG), Volume 1, Nomor 2, September 2013, hlm. 115-120

12. Chirstoper CK. Composite artisty using premise - the new breed of nanofiller. [serial online]. 2004 [cited 2010 Sep 29]; 138-42. Available from: URL:http://www. kerredental.com

13. Fortin D, Marcos AV. The spectrum of composites: new techniques and materials [serial online]. 2010 [cited $2010 \mathrm{Jul} \mathrm{04];} 29$. Avaibele from: URL: httpjada.ada.org

14. Erfinawati L. sifat-sifat fisik dan mekanis serta penggunaan resin kompposit flowable dalam kedektoran gigi [serial online]. 2008 [cited 2010 Sep 7]; 15. Available from; URL:http//www.researchgate.net

15. Idi AT. Polimerisasi sinar resin komposit. Medan: FKG Univesitas Sumatera Utara; 2004; p.3, 5-6.

16. Soraya SSM. Stabilitas warna resin komposit sebagai bahan tambalan. Medan: FKG Universitas Sumatera Utara [serial online]. 2010 [cited 2010 Okt 10]; 7. Available from: URL:http//www.research gate.net

17. Nursasingko B. restorasi estetik di bidang konservasi gigi. Jurnal Kedokteran Gigi. Bandung: KKG Universitas Padjadjaran; 2002; p.81-2.

18. Roberson TM, Harald OH, Edward JS. Sturdevan't Art and Science of Operative Denstry. India: Mosby, 2006; p.498-9, 503, 530-8.

19. Nainggolan $\mathbf{M}$. penggunaan resin komposit sebagai bahan pasak dan inti. Medan: FKG Universitas Sumatera Utrana [serial online]. 2008 [cited 2010 Okt 10]; 12. Avaible from : URL;http/www.researchgate.net

20. Devlin H. Operative Dentistry, A Practical Guide to Recent Innovations. Untited Kingdom: Springer, 2005; p.54.

21. McCabe JF, Angus WGW. Applied Dental Materials (Ninth Edition). Ausralia: Blackwell, 2008; p.237.
22. Effendi B. Pengaruh jarak penyinaran terhadap kekerasan permukaan resin komposit sinar tampak. Jurnal Kedokteran Gigi. Jakarta: PDGI, 2006; p.131.

23. Amanda L. Perbedaan pengaruh waktu pengeringan bahan adhesif terhadap shear bond strength restorasi klas I resin komposit. Medan: FKG Universitas Sumatera Utara; 2010; p.13, 17.

24. Hermina M. Perbaikan restorasi resin komposit klas I. Medan: FKG Universitas Sumatera Utara.

25. Kegagalan restorasi resin komposit dan solusinya [homepage on the Internet]. Nodate [cited 2010 Sep 10]. Available from: URL: www.doktergigibaik.wordpress.com

26. Jennifer AS, Catherine $H$, Felicia $T$, Mary T, Nancy CM. The longevity of amalgam versus compomer/composite restorations in posterior primary and permanent teeth: findings from the new England children's amalgam trial. J Am Dent Assoc. 2007;138:763-72.

27. Shah SA, Muntaha ST, Munir MB. Incidence of caries in 6-12 years children visiting Punjab dental hospital, Lahore, and sardar begum dental college and hospital and hospital, Peshawar. Pakistan Oral and Dental Journal. 2008;28(1):117-22.

28. Ziyad KMM. Microleakage in class 2 composite restoration bonded with different adhesive system [Thesis]. Universiti Sains Malaysia; 2008; 1-24.

29. Mendonca JS, Ranulfo GN, Sergio LS, Jose RPL, Maria FdLN, Ricardo MdC. Direct resin composite restorations versus composite inlays: one year result. J Contemp Dent Pract. 11(3):25-32.

30. Karaman E, Yazici AR, Gul O, Berrin D. Clinical evaluation of a nanohybrid and a flowable resin composite in non-carious cervical lesions: 24 month results. J Adhes Dent 2012. 